EDITORIAL

\title{
Coronary recanalisation, myocardial viability, and ventricular remodelling after infarction
}

\section{P G Camici}

.

It is important to identify the mechanisms that determine the progression to left ventricular remodelling after an acute myocardial infarction, in order that patients can be treated before the development of overt heart failure

Heart 2005;91:421-422. doi: 10.1136/hrt.2004.039065

occlusion of the left anterior descending coronary artery (LAD), who either underwent late percutaneous coronary intervention with stent to the LAD, or medical treatment alone. ${ }^{7}$ The study demonstrates that in the patients undergoing revascularisation, there was a significant relation between the number of viable segments within the infarct zone and improvement in end systolic volume index and ejection fraction, whereas in the medically treated group there was no relation between the number of viable segments in the infarct zone and the subsequent changes in systolic volume or ejection fraction.

The results of this investigation add to a large number of previous, non-randomised studies that provide a compelling message on the importance of looking for hibernating myocardium in patients with $\mathrm{CAD}$ and chronic left ventricular dysfunction. ${ }^{9}$ In this setting coronary revascularisation as a specific treatment for CHF provides not only significant symptomatic relief and improvement of life quality, but also confers a better prognosis. ${ }^{10}$ In principle, hibernating myocardium should be suspected in all patients with coronary artery disease and chronic left ventricular dysfunction of any degree ranging from regional dysfunction to ischaemic cardiomyopathy. Myocardial hibernation implies the concept of tissue viability, which can be diagnosed by non-invasive imaging modalities that detect either the presence of contraction reserve or the persistence of metabolic activity within chronically dysfunctional myocardial regions. ${ }^{9}$

\section{SYMPATHETIC NERVOUS SYSTEM ACTIVATION}

A number of other mechanisms contribute to left ventricular remodelling among which enhanced activation of the sympathetic nervous system plays a major role. Myocardial $\beta$ adrenoceptors $(\beta$-AR) are downregulated in patients with overt CHF and the degree of receptor downregulation is related to the severity of CHF. ${ }^{11}$ Furthermore, these patients have higher levels of circulating catecholamines that are inversely related to prognosis. $^{12}$

Positron emission tomography with the nonselective $\beta$-AR antagonist $S-\left[{ }^{11}\right.$ C] CGP 12177 allows the non-invasive measurement of regional myocardial $\beta$-AR density in humans in vivo, and Merlet and colleagues ${ }^{13}$ have demonstrated

\section{CORONARY RECANALISATION}

In this issue of Heart, Bellenger and colleagues ${ }^{7}$ provide evidence that coronary recanalisation, even at a late time after AMI (between three days and six weeks, mean of 26 days), can lead to attenuation of subsequent left ventricular remodelling. The authors studied a subset of patients from the open artery trial (TOAT). ${ }^{8}$ Dobutamine stress cardiovascular magnetic resonance (CMR) was used to assess myocardial viability in patients with anterior myocardial infarction, left ventricular dysfunction, and isolated proximal

Abbreviations: $A M I$, acute myocardial infarction; $\beta-A R$, myocardial $\beta$ adrenoceptors; CAD, coronary artery disease; CHF, chronic heart failure; $L A D$, left anterior descending coronary artery; CMR, cardiovascular magnetic resonance; TOAT, the open artery trial 


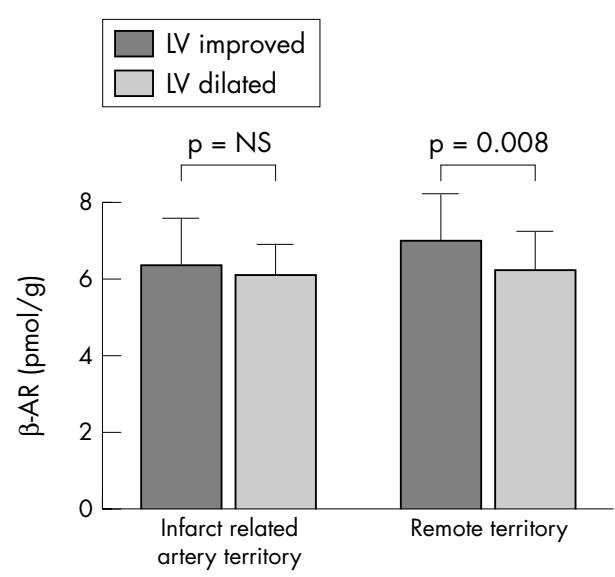

Figure 1 Myocardial $\beta$ adrenoceptor downregulation soon after acute myocardial infarction predicts left ventricular (LV) dilatation. $\beta-A R$, myocardial $\beta$ adrenoceptor density; LV improved, those patients $(\mathrm{n}=41)$ whose left ventricular volumes were found to be decreased six months after infarction; LV dilated, those patients $(n=20)$ whose left ventricular volumes were found to be increased six months after infarction. Adapted from Spyrou and colleagues. ${ }^{15}$

downregulation of $\beta$-AR in patients with CHF caused by idiopathic dilated cardiomyopathy. Using the same technique, our group demonstrated progressive $\beta$-AR downregulation in those patients with hypertrophic cardiomyopathy who proceed to left ventricular dilatation and CHF. ${ }^{14}$ More recently, in a prospective study of patients with AMI as their first presentation of $\mathrm{CAD}$, we have demonstrated that the degree of myocardial $\beta$-AR downregulation, measured in the subacute phase after AMI, is predictive of subsequent left ventricular remodelling assessed by serial measurements of left ventricular volumes up to six months after infarction (fig 1$).^{15}$

In summary, non-invasive imaging techniques allow measurements of physiological parameters that are strictly related to the development of left ventricular remodelling and CHF. Appropriate and timely use of these techniques allows proper patient stratification and optimisation of treatment strategies.

\section{REFERENCES}

1 Fox KF, Cowie MR, Wood DA, et al. Coronary heart disease as the cause of incident heart failure in the population. Eur Heart J 2001 ;22:228-36.

2 O'Connor CM, Hathaway WR, Bates ER, et al. Clinical characteristics and long-term outcome of patients in whom congestive heart failure develops after thrombolytic therapy for acute myocardial infarction: development of a predictive model. Am Heart J 1997;133:663-73.

3 Pfeffer MA, Braunwald E, Moye LA, et al. Effect of captopril on mortality and morbidity in patients with left ventricular dysfunction after myocardial infarction. Results of the survival and ventricular enlargement trial. The SAVE investigators. N Engl J Med 1992;327:669-77.

4 Khand A, Gemmel I, Clark AL, Cleland JG. Is the prognosis of heart failure improving? J Am Coll Cardiol 2000;36:2284-6.

5 Konstam MA. Progress in heart failure management? Lessons from the real world. Circulation 2000;102:1076-8.

6 Camici PG. Hibernation and heart failure. Heart 2004;90:141-3.

7 Bellenger NG, Yousef Z, Rajappan K, et al. Infarct zone viability influences ventricular remodelling after late recanalisation of an occluded infarct related artery. Heart 2005;91:478-83.

8 Yousef RY, Redwood SR, Bucknall CA, et al. Late intervention after anterior myocardial infarction: effects on left ventricular size, function, quality of life, and exercise tolerance: results of the open artery trial (TOAT study). J Am Coll Cardiol 2002;40:869-76.

9 Wijns W, Vatner SF, Camici PG. Hibernating myocardium. N Engl J Med 1998;339:173-81.

10 Pagano D, Lewis ME, Townend JN, et al. Coronary revascularisation for postischaemic heart failure: how myocardial viability affects survival. Heart 2000;83:456-61.

11 Fowler MB, Laser JA, Hopkins GL, et al. Assessment of the beta-adrenergic receptor pathway in the intact failing human heart: progressive receptor down-regulation and subsensitivity to agonist response. Circulation 1986;74:1290-302.

12 Cohn JN, Levine TB, Olivari MT, et al. Plasma norepinephrine as a guide to prognosis in patients with chronic congestive heart failure. $N$ Engl J Med 1984;311:819-23.

13 Merlet $P$, Delforge J, Syrota A, et al. Positron emission tomography with ${ }^{11} \mathrm{C}$ CGP-12177 to assess beta-adrenergic receptor concentration in idiopathic dilated cardiomyopathy. Circulation 1993:87:1 169-78.

14 Choudhury L, Guzzetti S, Lefroy D, et al. Myocardial $\beta$-adrenoceptor and left ventricular function in hypertrophic cardiomyopathy. Heart 1996;75:50-4.

15 Spyrou N, Rosen SD, Fath-Ordoubadi F, et al. Myocardial $\beta$-adrenoceptor density one month after acute myocardial infarction predicts left ventricular volumes at six months. J Am Coll Cardiol 2002;40:1216-24.

\section{IMAGES IN CARDIOLOGY}

\section{Cervical extradural haematoma following thrombolysis}

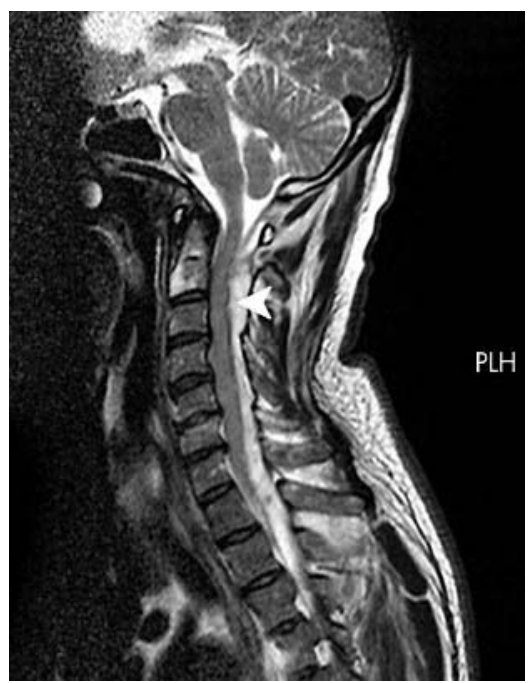

previously well 53 year old man presented with a three hour history of severe chest pain An ECG showed $4 \mathrm{~mm}$ ST segment elevation in the anterior leads. He received reteplase and clopidogrel (aspirin intolerance). Twelve hours later he developed severe neck pain with progressive tetraparesis with a sensory level at C6. Post-thrombolysis heparin and antiplatelet agents were stopped.

Magnetic resonance imaging of the spine (left) showed an extensive posterior extradural haemorrhage within the spinal canal from $\mathrm{C} 2$ and $\mathrm{T} 10$ with associated spinal cord compression at $\mathrm{C} 5 / 6$ and $\mathrm{C} 6 / 7$.

The patient was transferred as an emergency to the local neurosurgical centre where he underwent emergency evacuation of the haematoma. Seven days later, he had ongoing chest pain with dynamic ECG changes and underwent successful angioplasty to his left anterior descending coronary artery. He has since recovered full function in his upper limbs.

In thrombolysed patients, sudden neck pain should prompt suspicion of the rare, but recognised, complication of a cervical extradural haemorrhage. Urgent neurosurgery can significantly improve neurological prognosis. 